\title{
Outbreak Intervention for Bloodstream Infections Caused by Methicillin Resistant Coagulase-Negative Staphylococci in Neonatal Intensive Care Unit
}

Monika Brzychczy-Wloch ${ }^{1 *}$, Jadwiga Wojkowska-Mach ${ }^{1}$, Janusz Gadzinowski², Tomasz Opala ${ }^{2}$, Anna Szumala-Kakol ${ }^{2}$, Alicja Kornacka $^{2}$ Piotr B Heczko ${ }^{1}$ and Malgorzata Bulanda ${ }^{1}$

${ }^{1}$ Chair of Microbiology, Jagiellonian University Medical College, Krakow, Poland

${ }^{2}$ Gynecological and Obstetrics Clinical Hospital, Poznan University of Medical Science, Poznan, Poland

\begin{abstract}
Coagulase-negative staphylococci (CoNS) may cause severe infections in newborns hospitalised in Neonatal Intensive Care Units (NICU). The present study aimed to investigate the outbreak of bloodstream infections (BSI) caused by CoNS among 18 neonates in Polish NICU, including the implementation of preventive strategies. The outbreak period was observed from June to September 2009 in a group of 1016 newborns. To terminate the outbreak, an independent audit was performed in October 2009 by a team of experts. The post-intervention time lasted from January to March 2010. The genotype characteristics of CoNS derived from the blood samples and strains isolated from the NICU environment and staff hands were analysed by PCR (Polymerase Chain Reaction) and PFGE (Pulsed Field Gel Electrophoresis). In the outbreak period, the incidence density of BSI was 4.5/1000 patient days (pds), whereas that of CoNS BSI was 3.3/1000 pds. Generally, in the outbreak period, 18 cases of BSI caused by CoNS were registered with a large number of new cases in the $34^{\text {th }}$ week of 2009 , associated with a four-day-long public holiday. Both monomicrobial infections, as well as polymicrobial ones caused by multi-drug resistant Staphylococcus haemolyticus and Staphylococcus epidermidis, were noted. The result indicated high epidemic level of resistance genes among the CNS strains as well as horizontal spread of selected clones. After the intervention, when the preventive procedures had been standardized, a twofold decrease was recorded in the incidence rate of BSI from $4.5 / 1000$ pds in the outbreak time comparing to $2.4 / 1000$ pds in the post-intervention time. Our data support the view that CoNS are significant nosocomial pathogens in NICU and that some clones are transmitted between babies, through the hands of the staff. The research shows a failure to prepare Polish Infection Control Teams for crisis situations, such as an epidemic, and, at the same time, cautions against a similar occurrence in the future.
\end{abstract}

Keywords: Bloodstream infections; Neonatal intensive care unit; Outbreak; Coagulase-negative staphylococci; Hand hygiene

\section{Introduction}

Advances in care provided in Neonatal Intensive Care Units (NICU) have improved survival among very-low-birth weight (VLBW) infants, but healthcare-associated infections remain an important cause of morbidity and mortality in this high-risk population [1].

Coagulase-negative staphylococci(CoNS), which are members of the normal flora of the human skin, have emerged as important nosocomial pathogens during the past few decades [2]. CoNS, particularly Staphylococcus epidermidis and Staphylococcus haemolyticus, may cause severe infections in newborns, including meningitis or bacteraemia but, on the other hand, they are prevalent in the hospital environment and on the hands of health care workers [3]. Multiple drug resistance (MDR) has been widely documented among CoNS and probably reflects the adaptation of their nosocomial clones to the antibiotic selective pressure [4]. Colonization of patients and hospital staff with CoNS usually precedes infection with these organisms and constitutes a reservoir for antibiotic resistance genes [2]. To shed light on the clinical significance of CoNS in infections and provide data for control and epidemiological measures, reliable identification of this organism is crucial [3]. Several publications describing epidemiology of CoNS infections in NICU appeared within the last few years and emphasised increasing importance of these organisms in neonatal sepsis related to catheter use $[5,6]$.

The main aim of this study was to investigate the outbreak of CoNS bloodstream infections (BSI) among 18 neonates along with an implementation of preventive strategies.

\section{Materials and Methods}

\section{Ethical considerations}

The study was approved by Jagiellonian University Bioethical Committee decision no. KBET/94/B/2009.

\section{Hospital setting}

The Gynecological and Obstetrics Clinical Hospital facility with 410 beds located in a big city in the west of Poland was studied. There are approximately 4800 to 6300 live births per year in the centre and the admitted neonates are either born there or brought from nearby hospitals (about 5\%). The NICU in this hospital consists of 3 parts that surround a common storage and medicine dispensing area.

\section{The studied period}

The outbreak period was observed from June to September 2009

*Corresponding author: Monika Brzychczy-Wloch, Department of Bacteriology Microbial Ecology and Parasitology, Chair of Microbiology, Jagiellonian University Medical College,18 Czysta Street, 31-121 Cracow, Poland, Tel: +4812 63325 67; Fax: +4812 42339 24; E-mail: mbrzych@cm-uj.krakow.pl

Received April 13, 2013; Accepted May 15, 2013; Published May 20, 2013

Citation: Brzychczy-Wloch M, Wojkowska-Mach J, Gadzinowski J, Opala T, Szumala-Kakol A, et al. (2013) Outbreak Intervention for Bloodstream Infections Caused by Methicillin Resistant Coagulase-Negative Staphylococci in Neonata Intensive Care Unit. Clin Microbial 2: 115. doi:10.4172/2327-5073.1000115

Copyright: ( 2013 Brzychczy-Wloch M, et al. This is an open-access article distributed under the terms of the Creative Commons Attribution License, which permits unrestricted use, distribution, and reproduction in any medium, provided the original author and source are credited. 
Citation: Brzychczy-Wloch M, Wojkowska-Mach J, Gadzinowski J, Opala T, Szumala-Kakol A, et al. (2013) Outbreak Intervention for Bloodstream Infections Caused by Methicillin Resistant Coagulase-Negative Staphylococci in Neonatal Intensive Care Unit. Clin Microbial 2: 115. doi:10.4172/2327-5073.1000115

Page 2 of 7

(holiday period) for 11 weeks in the group of 1016 newborns. In this period of time, neonatologists and the infection control team registered 25 cases of BSI, which accounted for $62 \%$ of all infections. As BSI aetiological factors, CoNS were dominant (72\%) followed by Enterobacteriaceae (28\%). Generally, in the outbreak period, 18 cases of BSI caused by CoNS were registered with a large number of new cases in the $34^{\text {th }}$ week of 2009 , which was associated with a four-day-long public holiday.

To analyze and terminate the outbreak, an independent audit was performed in October 2009 by a team of experts from the Chair of Microbiology, Jagiellonian University Medical College in Krakow. Meetings were held with the nursing staff, neonatologists, nurse practitioners, pharmacy and infection control team to review patient records and establish a plan for decreasing the rate of infections in this high-risk group.

The post-intervention period lasted from January to March 2010 for 13 weeks in the group of 569 newborns. In that period of time, 12 new cases of BSI with CoNS aetiology were registered.

In order to compare the epidemiological situation in those two periods (outbreak period and post-intervention time), an epidemiological rate was applied. The incidence density per 1000 patient days (pds) was calculated according to the following formula: the ratio of new BSI occurrences in a specified quantity of person-time in the population at risk (patients of NICU) expressed as 1000 patient days (pds).

\section{Epidemiological investigation}

The inclusion criteria for the study group were the hospitalization in NICU for more than 2 days in the studied periods and occurrence of BSI caused by CoNS confirmed in a routine diagnostic procedure.

Medical and microbiological records were reviewed to identify instances of infection. Case patients of CoNS BSI were defined according to Gastmeier et al. as any neonate in the NICU who had clinical signs and/or symptoms of BSI had CoNS isolated from at least one blood culture [7].

In the outbreak period, 18 newborns with BSI caused by CoNS related to central venous catheterization (CVC) and/or peripheral venous catheterization (PVC) were included into a detailed analysis. In all of the cases, the first signs and symptoms of infection appeared in their third day of hospitalisation or later, and CVC or PVC was employed for at least 24 hours (Table 1).

\section{Microbiological Methods}

\section{Bacterial strains}

Standard laboratory methods were used to identify the microorganisms that grew from blood cultures.

Polymicrobial CoNS BSI was considered present if there was a record of a blood culture that yielded more than 1 causative organism belonging to the genus Staphylococcus [8].

We had to exclude strains from 4 newborns because relevant isolates were lost in hospital laboratory. Finally, we analysed the phenotype and genotype characteristics of 17 CoNS isolates derived from the blood samples of 14 investigated newborns. The investigated strains included 10 isolates of S. haemolyticus and 7 isolates of S. epidermidis.

Cultures were also performed on environmental samples from NICU, including patient-care and unit devices, e.g. incubators, respirators, as well as staff and parents' uniforms. Moreover, besides these samples, each member of the NICU staff was examined for the presence of dermatitis, or other skin lesions on the hands, and hand cultures were obtained. Environmental samples were collected during the course of the outbreak twice: 4-5.08.2009 and also 1824.08.2009. As a result, 21 methicillin resistant S. haemolyticus and 4 methicillin resistant $S$. epidermidis strains isolated from the

\begin{tabular}{|c|c|c|c|c|c|c|c|c|c|}
\hline $\begin{array}{c}\text { Patient } \\
\text { number [P] }\end{array}$ & $\begin{array}{c}\text { Sex } \\
\text { [F-female M-male] }\end{array}$ & $\begin{array}{l}\text { Gestatio-nal } \\
\text { age [weeks] }\end{array}$ & $\begin{array}{l}\text { Birth-weight } \\
{[\mathrm{g}]}\end{array}$ & $\begin{array}{c}\text { Infection day } \\
\text { [days] }^{*}\end{array}$ & CVC / PVC & $\begin{array}{l}\text { Length of catheteri- } \\
\text { zation [days] }\end{array}$ & $\begin{array}{c}\text { Paren-teral } \\
\text { nutrition }\end{array}$ & $\begin{array}{c}\text { Endo-tracheal } \\
\text { tube }\end{array}$ & $\begin{array}{c}\text { Naso-gastric } \\
\text { tube }\end{array}$ \\
\hline P1 & $\mathrm{F}$ & 28 & 1090 & 10 & PVC & 13 & Yes & Yes & Yes \\
\hline P2 & $\mathrm{F}$ & 31 & 1440 & 20 & PVC & 21 & Yes & No & Yes \\
\hline P3 & $M$ & 29 & 990 & 8 & CVC & 12 & Yes & Yes & Yes \\
\hline P4 & $M$ & ND & 1200 & 14 & CVC & 14 & Yes & ND & ND \\
\hline P5 & $M$ & 28 & 1240 & 17 & CVC & 17 & Yes & Yes & Yes \\
\hline P6 & $\mathrm{F}$ & 30 & 870 & 6 & CVC & 7 & Yes & No & Yes \\
\hline $\mathbf{P} 7^{\mathrm{D}}$ & M & 30 & 1320 & 7 & CVC & 7 & No & No & Yes \\
\hline P8 & $M$ & 26 & 1220 & 36 & ND & ND & Yes & Yes & Yes \\
\hline P9 & $\mathrm{F}$ & 33 & 1140 & 26 & PVC & 25 & Yes & No & Yes \\
\hline P10 & $\mathrm{F}$ & ND & ND & 10 & CVC & 10 & Yes & Yes & Yes \\
\hline P11 & $\mathrm{F}$ & ND & ND & 3 & No & 0 & No & ND & ND \\
\hline P12 & $M$ & 28 & 1255 & 27 & PVC & 25 & Yes & Yes & Yes \\
\hline P13 & $\mathrm{F}$ & 33 & 1400 & 12 & PVC & 12 & Yes & No & Yes \\
\hline P14 & $\mathrm{F}$ & 24 & 590 & 7 & PVC & 7 & Yes & Yes & Yes \\
\hline P15 & $\mathrm{F}$ & 29 & 850 & 27 & CVC & 27 & Yes & No & No \\
\hline P16 & $M$ & 32 & 1580 & 5 & CVC & 3 & Yes & No & No \\
\hline P17 & $M$ & 32 & 1610 & 12 & ND & ND & No & Yes & ND \\
\hline P18 & $M$ & ND & 1200 & 46 & ND & ND & Yes & ND & ND \\
\hline
\end{tabular}

(D) - death

(ND) - no data

*Infection day - The day of life when the infection was registered

**Length of catheterization - The length of catheterization before the infection

Table 1: Characteristics of 18 newborns with laboratory-confirmed BSI caused by coagulase-negative staphylococci. 
Citation: Brzychczy-Wloch M, Wojkowska-Mach J, Gadzinowski J, Opala T, Szumala-Kakol A, et al. (2013) Outbreak Intervention for Bloodstream Infections Caused by Methicillin Resistant Coagulase-Negative Staphylococci in Neonatal Intensive Care Unit. Clin Microbial 2: 115. doi:10.4172/2327-5073.1000115

Page 3 of 7

environment were included and analysed for their phenotype and genotype characteristics.

\section{Antibiotic susceptibility testing}

The resistance phenotypes were determined by disk diffusion method (Oxoid, England) according to CLSI guidelines [9].

\section{Multiplex PCR}

The presence of species-specific genes to $S$. haemolyticus or $S$. epidermidis and methicillin-resistance gene mecA was confirmed using multiplex PCR amplification according to Pereira et al. [10] with specific primers (Genomed, Poland): SH1 (5'-GGT CGC TTA GTC GA ACA AT-3'), SH2 (5'-CAC GAG CAA TCT CAT CAC CT-3'), SE1 (5'-ATC AAA AAG TTG GCG AAC CTT TTC A-3'), SE2 (5'CAA AAG AGC GTG GAG AAA AGT ATC A-3'), MRS1 (5'-TAG AAA TGA CTG AAC GTC CG-3') and MRS2 (5'-TTG CGA TCA ATG TTA CCG TAG-3'). The final pictures from electrophoresis were processed using QuantityOne software, as well as GelDoc2000 device (Bio-Rad, USA).

\section{PFGE and calculation of genetic similarity}

Isolates were genotyped by pulsed field gel electrophoresis (PFGE) according to GenePath Group1 protocol (Bio-Rad). Bacteria were cultured in $3 \mathrm{~mL}$ of Todd-Hewitt broth (Difco Laboratories, USA) at $37^{\circ} \mathrm{C}$ for $24 \mathrm{~h}$. DNA was digested using SmaI (MBI Fermentas, Latvia) and the fragments were separated in a CHEF-DR III device (Bio-Rad) using the program for Staphylococcus aureus for $24 \mathrm{~h}$ according to the manufacturer's instructions (Bio-Rad) with the following parameters, bloc 1: pulses $5-12 \mathrm{sec}, 5 \mathrm{~V} / \mathrm{cm}, 11 \mathrm{~h}, 12^{\circ} \mathrm{C}$; bloc 2: $20-60 \mathrm{sec}, 6 \mathrm{~V} / \mathrm{cm}$, $13 \mathrm{~h}, 12^{\circ} \mathrm{C}$. The genetic similarity between isolates was calculated using Molecular Analyst (Applied Maths, Belgium) software, making use of the Jaccard coefficient and unweighed pair group method with arithmetic mean (UPGMA). Genotype patterns were compared according to the guidelines of van Belkum et al. [11].

\section{Results}

In the outbreak period, 18 newborns with BSI caused by CoNS were included into a detailed analysis, from among 9 (50\%) were female and 9 (50\%) male, with the average value equal of: gestational age 29.5 weeks, birth-weight $1200 \mathrm{~g}$, infection day 16.2 and length of catheterization 13.3 days (Table 1).
In the study period, the incidence density of BSI in the group of neonates with low and VLBW was 4.5/1000 patient days (pds) from June to September 2009, whereas the incidence density of CoNS BSI was $3.3 / 1000$ pds. Mortality rate in the group of 18 newborns with BSI caused by CoNS was $11.1 \%$.

Average total length of hospitalisation in the outbreak period was 49.2 days, in opposition to average length of stay for patients in 2009 amounting to 5.4 days (95\% CI 0.3 - 10.2). Moreover, the mean duration of follow-up catheter until the first symptoms of BSI was 14.3 days (95\% CI 0.1-4.1).

A large number of new CoNS BSI cases were registered in the $34^{\text {th }}$ week of 2009 (Figure. 1), during which a four-day-long public holiday was held and the majority of the permanent unit staff was away on leave. They were then replaced in part by residents and younger nurses on duty.

The incidence of BSI in the post-intervention period (JanuaryMarch 2010) was 2.4/1000 pds with OR 0.3 (odds ratio per day) and 95\% CI (confidence interval) 15.4-23.0 (Figure. 1).

Multi-drug resistance of CoNS strains isolated from newborns was noted. Neonatal strains were resistant to methicillin, macrolides, aminoglycosides and fluoroquinolones in $100 \%, 88 \%, 88 \%$ and $76 \%$, respectively. All methicillin-resistance phenotype (MR) strains had mecA gene (Table 2).

Among the investigated patients with CoNS BSI, 9 newborns had monomicrobial infections, whereas 5 children had polymicrobial infections caused by S. haemolyticus and S. epidermidis (Table 2). Out of 9 newborns with monomicrobial infections, 7 children had $S$. haemolyticus isolated from blood samples (P1-P7), whereas 4 children (P8-P11) had S. epidermidis. In the group of 3 newborns (P12-P14) with polymicrobial infections, mixed infections caused by the same $S$. haemolyticus (PFGE type A) and S. epidermidis (PFGE type $\mathrm{A}^{*}$ ) clones were noted (Table 2, Figures 2 and 3).

PFGE analysis revealed that all investigated patients were infected with identical or closely related CoNS clones. Figure 2 shows the genetic similarity among selected strains of $S$. haemolyticus, 10 strains from patients (P1-P7, P12-P14) and 4 strains from the NICU environment (E1-E4). At a cut off level of $73 \%$ similarity, 2 clusters comprising 12 (cluster A) or 2 (cluster B) strains were identified. Figure 3 shows DNA macrorestriction profiles for selected strains of S. epidermidis, 7 from

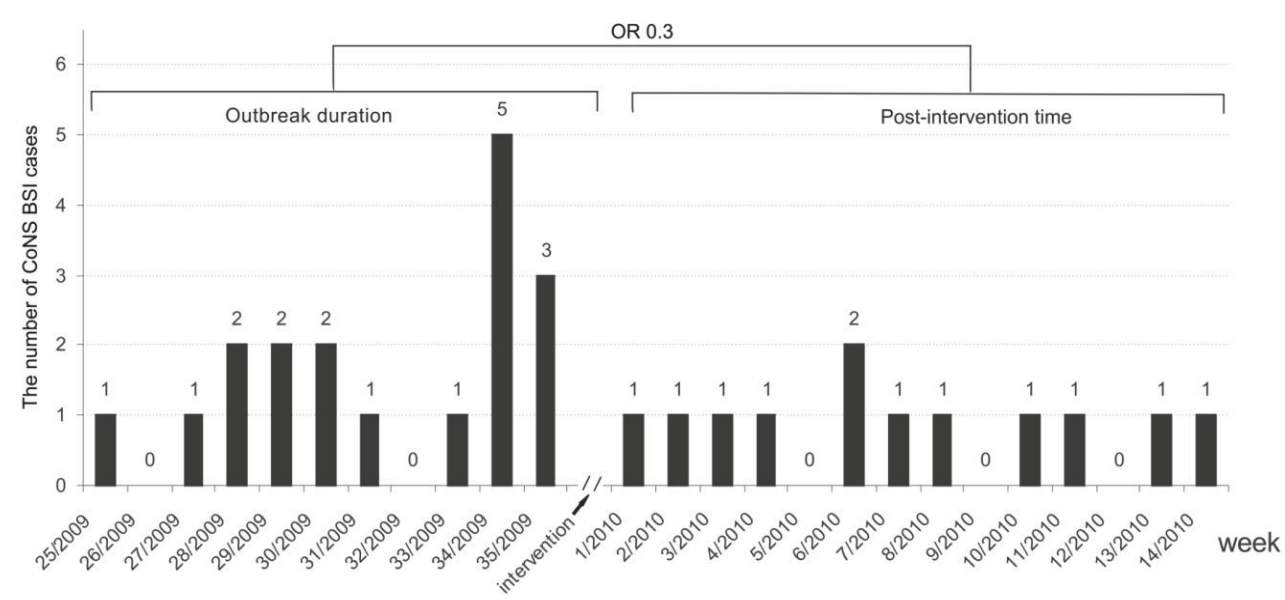

Figure 1: Weekly report of new cases of LCBSI caused by CoNS in the holiday period in the year 2009 and in the post-intervention time in 2010. 
Citation: Brzychczy-Wloch M, Wojkowska-Mach J, Gadzinowski J, Opala T, Szumala-Kakol A, et al. (2013) Outbreak Intervention for Bloodstream Infections Caused by Methicillin Resistant Coagulase-Negative Staphylococci in Neonatal Intensive Care Unit. Clin Microbial 2: 115. doi:10.4172/2327-5073.1000115

Page 4 of 7

\begin{tabular}{|c|c|c|c|c|c|c|c|c|}
\hline $\begin{array}{l}\text { Patient } \\
\text { number }\end{array}$ & Sample & Species & $\begin{array}{l}\text { Isolate number in } \\
\text { PFGE }\end{array}$ & PFGE type & $\begin{array}{l}\text { Methicillin } \\
\text { resistance } \\
\text { phenotype }\end{array}$ & $\begin{array}{l}\text { Macrolide } \\
\text { resistance } \\
\text { phenotype }\end{array}$ & $\begin{array}{l}\text { Amino- } \\
\text { glycosides } \\
\text { resistance }\end{array}$ & $\begin{array}{c}\text { Fluoro-quinolone } \\
\text { resistance }\end{array}$ \\
\hline P1 & blood & S. haemolyticus & P1/SH & A & MR & $\mathrm{MS}_{\mathrm{B}}$ & Present & Present \\
\hline P2 & blood & S. haemolyticus & $\mathrm{P} 2 / \mathrm{SH}$ & A & MR & $\mathrm{iMLS}_{\mathrm{B}}$ & Present & Present \\
\hline P3 & blood & S. haemolyticus & $\mathrm{P} 3 / \mathrm{SH}$ & A & MR & iMLS $_{B}$ & Present & Present \\
\hline P4 & blood & S. haemolyticus & P4/SH & A & MR & $\mathrm{MS}_{\mathrm{B}}$ & Absent & Absent \\
\hline P5 & blood & S. haemolyticus & P5/SH & A & MR & $\mathrm{CMLS}_{\mathrm{B}}$ & Present & Present \\
\hline P6 & blood & S. haemolyticus & $\mathrm{P} 6 / \mathrm{SH}$ & B & MR & $\mathrm{MS}_{\mathrm{B}}$ & Present & Present \\
\hline $\mathbf{P} 7^{\mathrm{D}}$ & blood & S. haemolyticus & P7/SH & B & MR & $\mathrm{CMLS}_{\mathrm{B}}$ & Present & Present \\
\hline P8 & blood & S. epidermidis & P8/SE & $\mathrm{B}^{*}$ & MR & $\mathrm{cMLS}_{\mathrm{B}}$ & Present & Present \\
\hline P9 & blood & S. epidermidis & P9/SE & $\mathrm{B}^{*}$ & MR & Absent & Present & Absent \\
\hline P10 & blood & S. epidermidis & P10/SE & $\mathrm{B}^{*}$ & MR & Absent & Present & Absent \\
\hline P11 & blood & S. epidermidis & P11/SE & $C^{*}$ & MR & $\mathrm{MS}_{\mathrm{B}}$ & Absent & Absent \\
\hline \multirow{2}{*}{ P12 } & \multirow{2}{*}{ blood } & S. haemolyticus & P12/SH & A & MR & $\mathrm{MS}_{\mathrm{B}}$ & Present & Present \\
\hline & & S. epidermidis & P12/SE & $A^{*}$ & MR & $\mathrm{MS}_{\mathrm{B}}$ & Present & Present \\
\hline \multirow{2}{*}{ P13 } & \multirow{2}{*}{ blood } & S. haemolyticus & P13/SH & $\mathbf{A}$ & MR & $\mathrm{iMLS}_{\mathrm{B}}$ & Present & Present \\
\hline & & S. epidermidis & P13/SE & $A^{*}$ & MR & $\mathrm{CMLS}_{\mathrm{B}}$ & Present & Present \\
\hline \multirow{2}{*}{ P14 } & \multirow{2}{*}{ blood } & S. haemolyticus & P14/SH & A & MR & $\mathrm{MS}_{\mathrm{B}}$ & Present & Present \\
\hline & & S. epidermidis & P14/SE & $A^{*}$ & MR & $\mathrm{CMLS}_{\mathrm{B}}$ & Present & Present \\
\hline
\end{tabular}

MR - methicillin resistance phenotype

iMLS $_{B}$ - inductive resistance to macrolides, lincosamides and streptogramins $B$

$\mathrm{CMLS}_{\mathrm{B}}$ - constitutive resistance to macrolides, lincosamides and streptogramins $B$

$M_{B}$ - resistance to macrolides and streptogramins B

PFGE type A - B for S. haemolitycus strains

PFGE type $A^{*}-C^{*}$ for $S$. epidermidis strains

(D) - death

Table 2: Characteristics of 17 coagulase-negative staphylococci (10 S. haemolyticus and 7 S. epidermidis strains) isolated from 14 newborns with laboratory-confirmed BSI

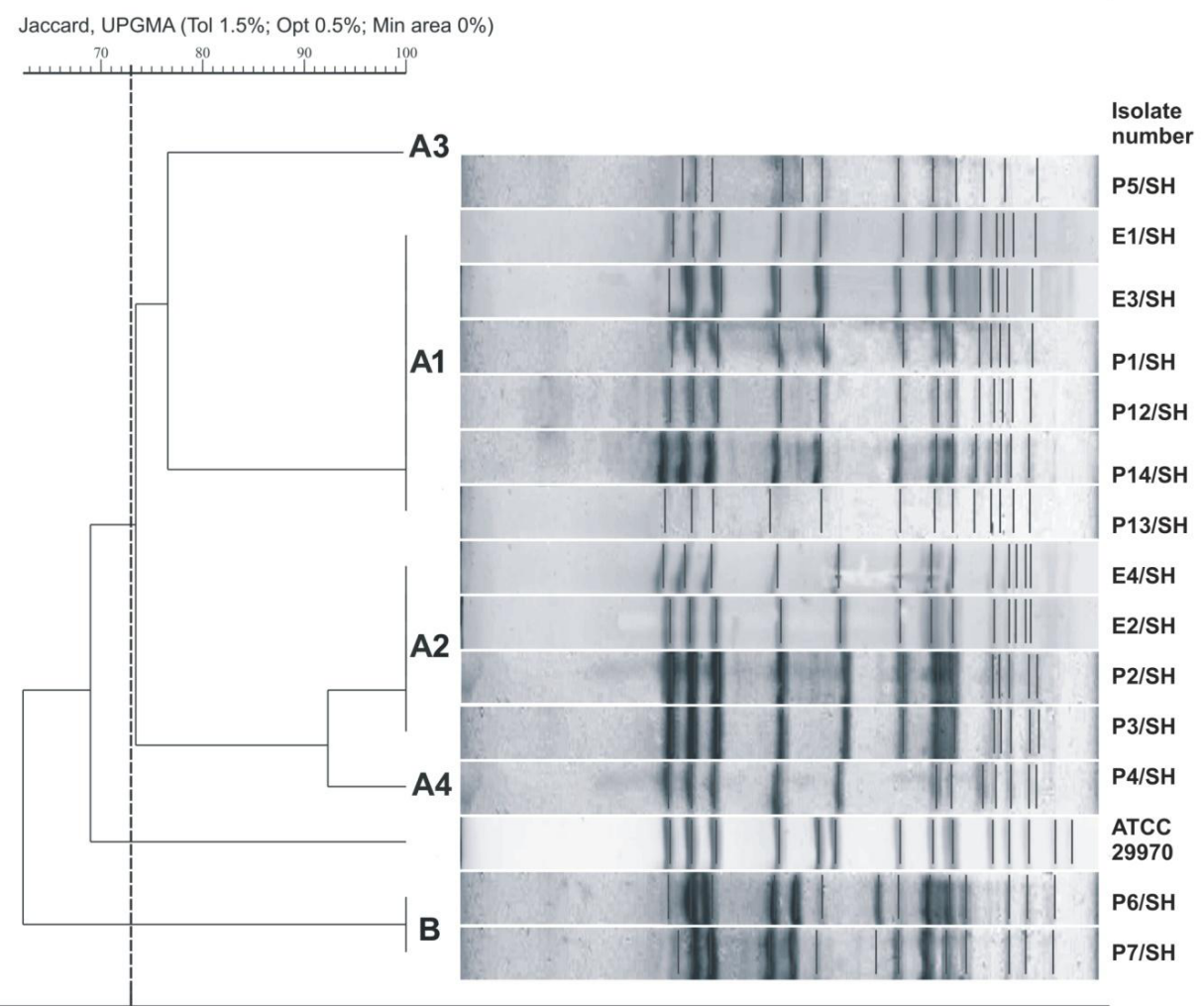

Figure 2: Cluster analysis of PFGE patterns following Smal restriction enzyme digestion of chromosomal DNA from $15 \mathrm{~S}$. haemolyticus (SH) isolates: 10 strains originating from patients (P1-P7, P12-P14), 4 from the environment (E1-E4) and 1 reference strain (ATCC 29970). Strains belonging to the same group (PFGE type) were clustered at a level of $73 \%$ similarity (dashed line). 
Citation: Brzychczy-Wloch M, Wojkowska-Mach J, Gadzinowski J, Opala T, Szumala-Kakol A, et al. (2013) Outbreak Intervention for Bloodstream Infections Caused by Methicillin Resistant Coagulase-Negative Staphylococci in Neonatal Intensive Care Unit. Clin Microbial 2: 115. doi:10.4172/2327-5073.1000115

Page 5 of 7

Jaccard UPGMA (Tol 1.5\%; Opt 0.5\%, Min area 0\%)

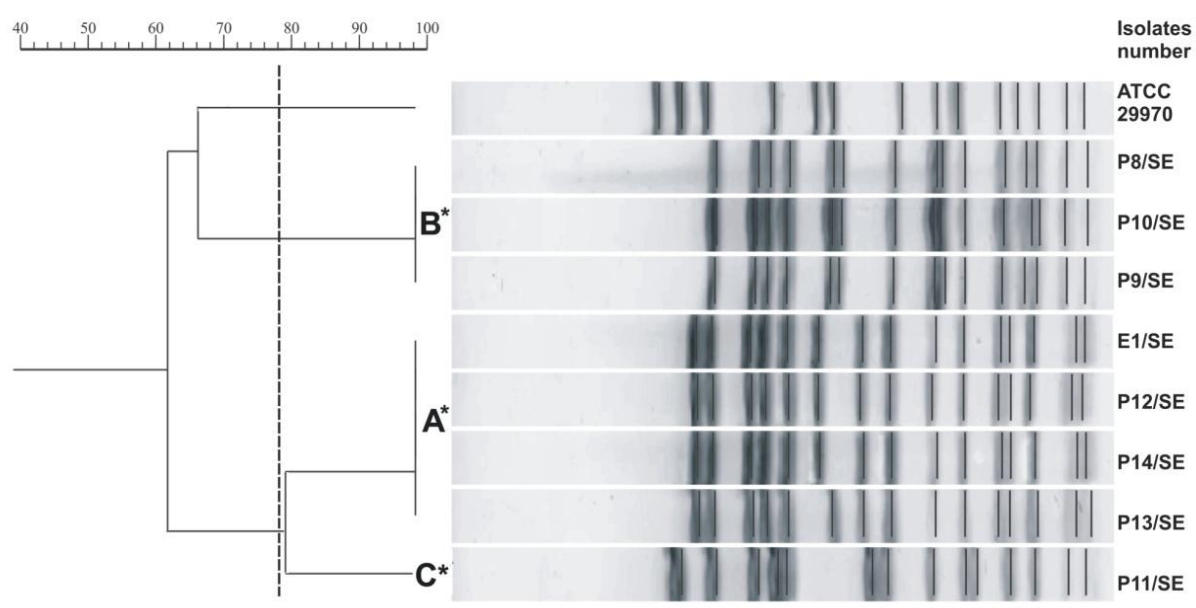

Figure 3: Cluster analysis of PFGE patterns following Smal restriction enzyme digestion of chromosomal DNA from 9 S. epidermidis (SE) isolates: 7 strains originating from patients (P8-P14), 1 from the environment (E1) and 1 reference strain (ATCC 29970). Strains belonging to the same group (PFGE type) were clustered at a level of $78 \%$ similarity (dashed line).

patients (P8-P14) and 1 from the environment (E1). At a cut off level of $78 \%$ similarity, 3 clusters were noticed, comprising 4 (cluster $\left.A^{\star}\right), 3$ (cluster $\mathrm{B}^{*}$ ) and 1 (cluster $\mathrm{C}^{*}$ ) strains with identical profiles.

Out of 21 methicillin-resistant $S$. haemolyticus strains isolated from the environment, four isolates were admitted to the cluster A (Figure 2), from which two strains, E1SH and $\mathrm{E} 3 \mathrm{SH}$, were isolated from medical personnel's hands, whereas E2SH and E4SH originated from the incubator and staff uniform, respectively. Out of 4 methicillin-resistant S. epidermidis strains isolated from the environment, one strain (E1SE) originating from the respirator was identified as PFGE type $\mathrm{A}^{\star}$ (Figure $3)$.

\section{Termination of the outbreak}

The audit performed in October 2009 by an independent expert team from the Chair of Microbiology, Jagiellonian University Medical College in Krakow helped the local unit to establish a plan for decreasing the rate of infections in this high-risk group. The Three Step Plan was developed to address high infection rates. The following procedures, according to CDC recommendations, were standardized: hand hygiene, skin preparation, frequency and hygiene of line changes, blood culture collections and dressing changes [12,13]. All these modifications resulted in a positive outcome both for the infants, decreasing incidence rate of BSI from $4.5 / 1000$ pds to $2.4 / 1000 \mathrm{pds}$, and the nursing and medical staff.

\section{Discussion}

Newborn babies treated in NICU, particularly prematurely born and newborns with VLBW are prone to developing infections. It is associated both with newborn immune system immaturity and with the need to perform many invasive diagnostic and therapeutic procedures [14-16].

There are great difficulties with studying the results of blood cultures from premature infants. Interpretation of blood cultures that are positive for CoNS is particularly difficult because these organisms live on the skin and mucous during the collection process. The neonatologists in our NICU do not obtain blood samples unless a patient has clinical signs and a syndrome compatible with bacteraemia according to Gastmaier et al. [7]. Isolation of CoNS from a single blood culture under these circumstances neither rules out contamination nor establishes a definitive diagnosis. A similar problem was discussed by Sidebottom et al. and Huang et al. These scientists indicated that the newborns with a CoNS-positive single blood culture had, in fact, bacteraemia $[17,18]$.

In the hospital epidemiology, where exposure to the occurrence of infection depends on the length of hospitalization and length of device use, especially in NICU, incidence density is usually used. Incidence associated with BSI in previous study reached 8.5/1000 pds in newborns weighing $<1000 \mathrm{~g}$ to $4 / 1000 \mathrm{pds}$ in neonates up to $1500 \mathrm{~g}$ $[19,20]$. In our study, the incidence of BSI was high, despite the fact that the study group consisted of both healthy children and low and VLBW newborns. The high incidence rate was correlated both with CVC and with PVC, which showed important risk factor of BSI at the examined centre. Some studies have found similar association between different types of catheter and BSI [21].

Despite the importance of CoNS as a cause of hospital acquired infections, limited information has been available regarding their reservoirs, distribution, and mode of transmission within the hospital environment. CoNS are members of the human skin flora of adult people but certain epidemic strains can colonize skin for extended periods of time, and transient hand carriage of such strains is thought to be a mode of transmission when no source is identified [22].

Our study demonstrated the occurrence and spread of identical, or closely related, CoNS clones, between newborns. Furthermore, identical CoNS were isolated from the hospital environment, especially from medical staff hands, which suggested that the transmission of CoNS could occur between babies via the staff hands. Thus, molecular studies indicated horizontal spread of selected clones. These findings correlate with Raimundo et al. who add to the increasing evidence that 
Citation: Brzychczy-Wloch M, Wojkowska-Mach J, Gadzinowski J, Opala T, Szumala-Kakol A, et al. (2013) Outbreak Intervention for Bloodstream Infections Caused by Methicillin Resistant Coagulase-Negative Staphylococci in Neonatal Intensive Care Unit. Clin Microbial 2: 115. doi:10.4172/2327-5073.1000115

epidemic clones of S. epidermidis may become established in NICU and transmitted between babies [23]. Monsen et al. [4] suggested that clonal spread of CoNS may occur within and even between wards. Similarly, Takei et al. [24] showed the transmission of MRSA/MRCNS in the old NICU of Hospital A and the relocated NICU (new NICU). A homology study of MRSA/MRCNS strains by PFGE DNA restriction patterns identified genotypes that showed similar patterns in the nurses' palms, towels, infant incubators, and room air. Genetic analysis carried out by Hira et al. [25] showed that $90 \%$ of the CoNS blood isolates were closely related to the strains found on the personnel's hands and in the hospital environment and they differed from those in the general population. In our study, the detected clones, e.g. S. haemoliticus PFGE type A, were found and remained in the NICU during the study period of almost three months. These findings corroborate results from other reports indicating that certain clones of CoNS may persist over time in certain wards, and that such clones often seem to be ward-specific, reflecting the antibiotic consumption in the paediatric ward $[2,4]$.

Our study indicated high level (21\%) of polymicrobial PVPassociated BSI caused by S. haemolyticus and S. epidermidis. Data on polymicrobial BSI in neonates are extremely limited. A high percentage of polymicrobial CVC-associated BSIs among paediatric patients receiving outpatient therapy has been noted in recent years [8]. Polymicrobial BSIs are problematic for clinicians, because appropriate treatment frequently requires multiple broad-spectrum antibiotics [26]. Downes et al. [26] hypothesized that certain risk factors may predispose children to the development of polymicrobial BSIs. Polymicrobial BSIs are relatively common in hospitalized neonates, occurring in approximately $3 \%$ to $10 \%$ of cases of neonatal BSI [8]. Bizzaro et al.'s [8] study confirmed the association of polymicrobial BSI in infants with the presence of severe underlying conditions. Moreover, the described situation might have been connected to the ability of CoNS to create mixed biofilms on medical devices, from which they can easily spread to the blood of neonates, who are particularly susceptible to this kind of infections.

In most cases, catheter-associated BSI (CABSI) can be prevented. Thus, hospital policies and care procedures should be directed toward the adoption of preventive measures rather than merely the identification and treatment of CABSI. During the past 15 years, there have been major advances in understanding the epidemiology and pathogenesis of CABSI in adult population. The concept described by Sax et al. [27] showed that hand hygiene and educational programs were related to a significant reduction in infection rates.

An important risk factor for BSI in the studied period was inadequate hand hygiene of staff which may be linked to less intensively trained doctors and nurses on duty during holidays. Unfortunately, appropriate action concerning changes in the situation on the ward, including hygiene behavior, were taken in the joint action of microbiologists and neonatologists four months after the first observation of the outbreak. In the light of the results achieved, we are fully aware of the causes of the existing situation and sub-optimal infection control. The cooperation between studied NICU staff and the infection control team as well as the expert team permitted to review the patients' records and establish a plan for decreasing the rate of infections in this high-risk group. The modifications resulted in a positive outcome for the infants and the nursing as well as medical staff.

The presented results come from the Polish NICU and are first to describe the procedure associated with epidemic and extinguishing outbreaks by education on hand hygiene. It confirms the fact that, particularly in NICU, rigorous infection control measures such as strict isolation, environmental cleaning, staff education and proper hand hygiene are very important, in particular to terminate an on-going outbreak and prevent new infections. Moreover, the described situation has shown a failure to prepare Polish infection control teams for crisis situations, which an epidemic is.

In summary, the investigated BSI caused by coagulase-negative staphylococci in the Neonatal Intensive Care Unit appeared due to clonal dissemination, therefore, it was potentially preventable by strict adherence to the recommended infection control practices and the implementation of programs aimed at the reduction of unnecessary use of antibiotics.

\section{Acknowledgements}

This study was supported by a grant from the National Centres of Science no. N N401 615340.

\section{References}

1. Geffers C, Baerwolff S, Schwab F, Gastmeier P (2008) Incidence of healthcareassociated infections in high-risk neonates: results from the German surveillance system for very-low-birthweight infants. J Hosp Infect 68: 214-221.

2. Widerstrom M, Monsen T, Karlsson C, Wistrom J (2006) Molecular epidemiology of meticillin-resistant coagulase-negative staphylococci in a Swedish county hospital: evidence of intra- and interhospital clonal spread. J Hosp Infect 64 : 177-183.

3. Schuenck RP, Pereira EM, lorio NL, Dos Santos KR (2008) Multiplex PCR assay to identify methicillin-resistant Staphylococcus haemolyticus. FEMS Immunol Med Microbiol 52: 431-435.

4. Monsen T, Rönnmark M, Olofsson C, Wiström J (1999) Antibiotic susceptibility of staphylococci isolated in blood cultures in relation to antibiotic consumption in hospital wards. Scand J Infect Dis 31: 399-404.

5. van den Hoogen A, Gerards LJ, Verboon-Maciolek MA, Fleer A, Krediet TG (2010) Long-term trends in the epidemiology of neonatal sepsis and antibiotic susceptibility of causative agents. Neonatology $97: 22-28$.

6. Orsi GB, d'Ettorre G, Panero A, Chiarini F, Vullo V, et al. (2009) Hospitalacquired infection surveillance in a neonatal intensive care unit. Am J Infect Control 37: 201-203

7. Gastmeier P, Geffers C, Schwab F, Fitzner J, Obladen M, et al. (2004) Development of a surveillance system for nosocomial infections: the component for neonatal intensive care units in Germany. J Hosp Infect 57: 126-131.

8. Bizzarro MJ, Dembry LM, Baltimore RS, Gallagher PG (2008) Matched casecontrol analysis of polymicrobial bloodstream infection in a neonatal intensive care unit. Infect Control Hosp Epidemiol 29: 914-920.

9. CLSI (2009) Performance standards for antimicrobial disk susceptibility tests; approved standard - tenth edition, M02-A10, 29: 1.

10. Pereira EM, Schuenck RP, Malvar KL, lorio N, Matos P, Olendzki A, et al. (2010) Staphylococcus aureus, Staphylococcus epidermidis and Staphylococcus haemolyticus: Methicillin-resistant isolates are detected directly in blood cultures by multiplex PCR. Microbiol Res 165: 243-249.

11. van Belkum A, Tassios PT, Dijkshoorn L, Haeggman S, Cookson B, et al. (2007) Guidelines for the validation and application of typing methods for use in bacterial epidemiology. Clin Microbiol Infect 13 Suppl 3: 1-46.

12. Boyce JM, Pittet D (2002) Guideline for Hand Hygiene in Health-Care Settings: recommendations of the Healthcare Infection Control Practices Advisory Committee and the HICPAC/SHEA/APIC/IDSA Hand Hygiene Task Force. Infect Control Hosp Epidemiol 23:3-40.

13. O'Grady NP, Alexander M, Dellinger EP, Gerberding JL, Heard SO, et al. (2002) Healthcare Infection Control Practices Advisory Committee: Guidelines for the prevention of intravascular catheter-related infections. Infect Control Hosp Epidemiol 23: 759-769.

14. Garland JS, Alex CP, Sevallius JM, Murphy DM, Good MJ, et al. (2008) Cohort study of the pathogenesis and molecular epidemiology of catheter-related bloodstream infection in neonates with peripherally inserted central venous catheters. Infect Control Hosp Epidemiol 29: 243-249.

15. Gastmeier P, Loui A, Stamm-Balderjahn S, Hansen S, Zuschneid I, et al. (2007) 
Citation: Brzychczy-Wloch M, Wojkowska-Mach J, Gadzinowski J, Opala T, Szumala-Kakol A, et al. (2013) Outbreak Intervention for Bloodstream Infections Caused by Methicillin Resistant Coagulase-Negative Staphylococci in Neonatal Intensive Care Unit. Clin Microbial 2: 115. doi:10.4172/2327-5073.1000115

Page 7 of 7

Outbreaks in neonatal intensive care units - they are not like others. Am J Infect Control 35: 172-176.

16. Shah SS, Downes KJ, Elliott MR, Bell LM, McGowan KL, et al. (2008) How long does it take to "rule out" bacteremia in children with central venous catheters? Pediatrics 121: 135-141.

17. Sidebottom DG, Freeman J, Platt R, Epstein MF, Goldmann DA (1988) Fifteenyear experience with bloodstream isolates of coagulase-negative staphylococci in neonatal intensive care. J Clin Microbiol 26: 713-718.

18. Huang YC, Wang YH, Chou YH, Lien RI (2006) Significance of coagulasenegative staphylococci isolated from a single blood culture from neonates in intensive care. Ann Trop Paediatr 26: 311-318.

19. National Nosocomial Infections Surveillance System (2004) National Nosocomial Infections Surveillance (NNIS) System Report, data summary from January 1992 through June 2004, issued October 2004. Am J Infect Control 32: $470-485$

20. Gaynes RP, Martone WJ, Culver DH, Emori TG, Horan TC, et al. (1991) Comparison of rates of nosocomial infections in neonatal intensive care units in the United States. National Nosocomial Infections Surveillance System. Am J Med 91: 192-196.

21. Geffers C, Gastmeier A, Schwab F, Groneberg K, Rüden H, et al. (2010) Use of central venous catheter and peripheral venous catheter as risk factors for nosocomial bloodstream infection in very-low-birth-weight infants. Infect Control Hosp Epidemiol 31: 395-401.

22. Monsen T, Karlsson C, Wiström J (2005) Spread of clones of multidrugresistant, coagulase-negative staphylococci within a university hospital. Infect Control Hosp Epidemiol 26: 76-80.

23. Raimundo O, Heussler H, Bruhn JB, Suntrarachun S, Kelly N, et al. (2002) Molecular epidemiology of coagulase-negative staphylococcal bacteraemia in a newborn intensive care unit. J Hosp Infect 51: 33-42.

24. Takei Y, Yokoyama K, Katano H, Tsukiji M, Ezaki T (2010) Molecula epidemiological analysis of methicillin-resistant staphylococci in a neonatal intensive care unit. Biocontrol Sci 15: 129-138.

25. Hira V, Sluijter M, Goessens WH, Ott A, de Groot R, et al. (2010) Coagulasenegative staphylococcal skin carriage among neonatal intensive care unit personnel: from population to infection. J Clin Microbiol 48: 3876-3881.

26. Downes KJ, Metlay JP, Bell LM, McGowan KL, Elliott MR, et al. (2008) Polymicrobial bloodstream infections among children and adolescents with central venous catheters evaluated in ambulatory care. Clin Infect Dis 46: 387 394.

27. Sax H, Allegranzi B, Uçkay I, Larson E, Boyce J, et al. (2007) 'My five moments for hand hygiene': a user-centred design approach to understand, train, monitor and report hand hygiene. J Hosp Infect 67: 9-21. 